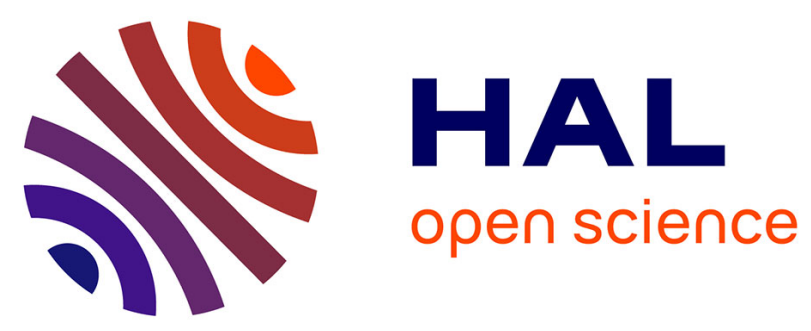

\title{
Methyl-3-Hexenoate Combustion Chemistry: Experimental Study and Numerical Kinetic Simulation
}

Ilya E Gerasimov, Denis A Knyazkov, Tatyana A Bolshova, Andrey G Shmakov, Oleg P Korobeinichev, Maxime Carbonnier, Benoîte Lefort, Alan Kéromnès, Luis Le Moyne, Marco Lubrano Lavadera, et al.

\section{To cite this version:}

Ilya E Gerasimov, Denis A Knyazkov, Tatyana A Bolshova, Andrey G Shmakov, Oleg P Korobeinichev, et al.. Methyl-3-Hexenoate Combustion Chemistry: Experimental Study and Numerical Kinetic Simulation. Combustion and Flame, 2020, 222, pp.170-180. 10.1016/j.combustflame.2020.08.028 . hal02934473

\section{HAL Id: hal-02934473 \\ https://hal.science/hal-02934473}

Submitted on 9 Sep 2020

HAL is a multi-disciplinary open access archive for the deposit and dissemination of scientific research documents, whether they are published or not. The documents may come from teaching and research institutions in France or abroad, or from public or private research centers.
L'archive ouverte pluridisciplinaire HAL, est destinée au dépôt et à la diffusion de documents scientifiques de niveau recherche, publiés ou non, émanant des établissements d'enseignement et de recherche français ou étrangers, des laboratoires publics ou privés.

$$
\text { Copyright }
$$




\title{
Methyl-3-Hexenoate Combustion Chemistry: Experimental Study and Numerical Kinetic Simulation
}

\author{
Ilya E. Gerasimov ${ }^{1,2, *}$, Denis A. Knyazkov ${ }^{2,3}$, Tatyana A. Bolshova ${ }^{2}$, Andrey G. Shmakov $^{2,3}$, \\ Oleg P. Korobeinichev ${ }^{2}$, Maxime Carbonnier ${ }^{1,4}$, Benoîte Lefort ${ }^{4}$, Alan Kéromnès ${ }^{4}$, Luis Le \\ Moyne $^{4}$, Marco Lubrano Lavadera ${ }^{5}$, Alexander A. Konnov ${ }^{5}$, Chong-Wen Zhou ${ }^{6}$, Zeynep \\ Serinye $^{1,7}$, Guillaume Dayma ${ }^{1,7}$, Philippe Dagaut ${ }^{1}$
}

${ }^{1}$ CNRS-INSIS, Institut de Combustion, Aérothermique, Réactivité et Environnement, Orléans, France

${ }^{2}$ Voevodsky Institute of Chemical Kinetics and Combustion, Novosibirsk, Russia

${ }^{3}$ Novosibirsk State University, Novosibirsk, Russia

${ }^{4}$ DRIVE EA1859, Université de Bourgogne - Franche Comté, Nevers, France

${ }^{5}$ Combustion Physics, Lund University, Lund, Sweden

${ }^{6}$ School of Energy and Power Engineering, Beihang University, Beijing, PR China

${ }^{7}$ Université d'Orléans, Orléans, France

Keywords: Methyl-3-hexenoate; Flame structure; Oxidation, Ignition, Burning velocity.

\begin{abstract}
This work represents a detailed investigation of combustion and oxidation of methyl-3-hexenoate (CAS Number 2396-78-3), including experimental studies of combustion and oxidation characteristics, quantum chemistry calculations and kinetic model refinement. Following experiments have been carried out: Speciation measurements during oxidation in a jet-stirred reactor at $1 \mathrm{~atm}$; chemical speciation measurements in a stoichiometric premixed flame at $1 \mathrm{~atm}$ using molecular-beam mass-spectrometry; ignition delay times measurements in a shock tube at 20 and 40 bar; and laminar burning velocity measurements at 1 atm using a heat-flux burner over a range of equivalence ratios. An updated detailed chemical kinetic mechanism for methyl-3hexenoate combustion based on previous studies was proposed and validated against the novel experimental data and the relevant data available in literature with satisfactory agreement. Sensitivity and reaction pathway analyses were performed to show main decomposition pathways of methyl-3-hexenoate and underline possible sources of disagreements between experiments and simulations.
\end{abstract}

\section{Introduction}

Biodiesel, which is a blend of methyl esters of fatty acids, is a clean-burning renewable fuel as compared to petroleum fuels $[1,2]$. Derived mostly from the process of transesterification of vegetable oils with methanol, biodiesel has been extensively studied experimentally and numerically during the last decade. This allowed significant advances in understanding the processes occurring during its oxidation and in the development of several detailed kinetic combustion mechanisms [3]. Composition of biodiesel includes unsaturated esters with varying degree of unsaturation, for example methyl oleate, methyl linoleate, methyl linolenate. Moreover, unsaturated esters are known to be important intermediates in combustion and oxidation of saturated esters, as well as biodiesel and its surrogates $[4,5]$. The unsaturated esters have several additional classes of reactions, comparatively to saturated esters, and different investigations have shown that the presence of one or more double bonds in their alkyl chain considerably affect their chemical and physical properties [2]. Thereby, development of kinetic mechanisms suitable for representing real biodiesel fuels requires a good understanding of the combustion chemistry of unsaturated esters.

In this regard, combustion chemistry of the simplest esters with unsaturated alkyl chain, like methyl-2-butenoate (methyl crotonate) and methyl methacrylate, has been investigated experimentally and numerically [6-9]. However, these small esters have too short alkyl chains to 
be regarded as surrogate biodiesel fuels $[6,10]$. Therefore, combustion chemistry of esters with long alkyl chain and with different degree of unsaturation has been of particular interest over recent years to reveal the impact of $\mathrm{C}=\mathrm{C}$ double bond on combustion characteristics of biodiesel and its surrogates.

Investigation of methyl oleate (methyl-9-octadecenoate) oxidation in a jet-stirred reactor (JSR) by Bax et al. [11] has shown that unsaturated compounds can produce a specific set of intermediate species as a result of the addition reactions of $\mathrm{H}, \mathrm{OH}$ or $\mathrm{HO}_{2}$ to the double bond. Several research teams studied autoignition of different fuel blends with large unsaturated esters and all have demonstrated that the position of the double bond in ester alkyl chain has a substantial influence on its oxidation rate $[4,12,13]$. In particular, the presence of the double bond reduces the rates of radical isomerization reactions if the double bond is embedded in the transition state ring. These reactions normally accelerate the overall rate of low temperature combustion, and thus double bond has a lesser effect if situated near the free end of the hydrocarbon chain. Similar results were obtained by Zhang et al. [14]: experiments on the autoignition of n-heptane/methyl hexanoate and n-heptane/methyl-3-hexenoate fuel blends have shown that unsaturated esters have smaller low-temperature reactivity compared to alkanes and their decomposition pathways include reactions of addition to the double bond.

In further studies, a detailed combustion mechanism for methyl stearate and methyl oleate [15], as well as other components of soy and rapeseed biodiesel fuels [5] (including unsaturated esters) was proposed. This mechanism was validated on experimental data on oxidation of the rapeseed oil methyl esters in a JSR presented earlier by Dagaut et al. [16], and a good agreement was achieved. Additional refinement of this model was performed by Campbell et al. [17] using the data on ignition delay times of methyl oleate and methyl linoleate in an aerosol shock tube. Authors achieved a good agreement with available experimental data by updating thermochemical parameters of the initial fuel molecules in the mechanism.

Rodriguez et al. [18] studied oxidation in a JSR at $1 \mathrm{~atm}$ of three components of biodiesel fuels: methyl stearate (saturated alkyl chain), methyl oleate (one $\mathrm{C}=\mathrm{C}$ double bond in alkyl chain) and methyl linoleate (two $\mathrm{C}=\mathrm{C}$ double bonds in alkyl chain) to address the effect of unsaturation on chemical kinetics. Authors used their experimental results for the refinement of their lumped kinetic model for biodiesel oxidation published earlier [19] in order to provide a more efficient approach to the simulation of biodiesel fuels. One of the main results of this work is that the mechanism is complemented with the reactions of $\mathrm{OH}$ radical addition to the double bond with subsequent decomposition of initial fuel molecules also called Waddington mechanism [20]. This class of reactions has a considerable impact on a low-temperature oxidation of unsaturated species and therefore it was necessary to address difference in low-temperature reactivity between these three esters.

Despite the achieved progress in development of detailed chemical kinetic models for combustion of major components of biodiesel fuels, significant difficulties still remain. Particularly, due to a huge number of species and reactions in the proposed kinetic mechanisms, most reaction rate constants, including those specific for unsaturated esters, are roughly estimated and require revisiting. In this regard, the combustion kinetics of esters with unsaturated aliphatic chain of moderate length, may appear as more simple, however still represent adequate surrogates of biodiesel components. Methyl-3-hexenoate ( $m h x 3 d)$ is one of such representatives (see Fig. 1). However, the studies of its combustion chemistry are fairly scarce [21, 22].

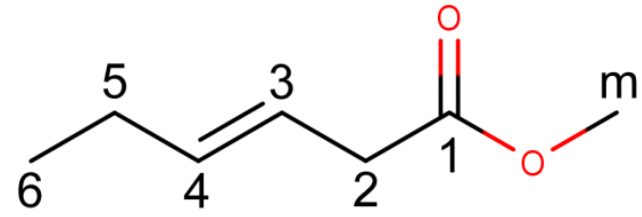

Fig. 1. Chemical structure of Methyl-3-hexenoate and designation of carbon atoms.

Zhang et al. [21] studied the oxidation of methyl-3-hexenoate ( $m h x 3 d)$ in a JSR at $10 \mathrm{~atm}$ for 3 different equivalence ratios and used these data to validate a new chemical kinetic mechanism 
based on their previous studies of methyl hexanoate. A careful refinement of the mechanism provided a very good agreement between experiments and simulations for many intermediate species measured in these conditions. Autoignition of $m h x 3 d$ at fuel-lean conditions and at 10.5 atm was studied by Wagnon et al. [22] using a rapid compression machine (RCM). Simulations were performed with a new mechanism based on Herbinet et al. [12] and the mechanism of Zhang et al. [21]. This work identified several reaction pathways which require a more thorough investigation due to significant differences in reaction rate constants compared to saturated esters.

This work represents a continuation in the development of a detailed kinetic mechanism for combustion and oxidation of methyl-3-hexenoate $(m h \times 3 d)$ to achieve a better understanding of combustion chemistry of unsaturated esters. As seen from the literature survey provided above, only experimental data on $m h x 3 d$ oxidation and autoignition at about 10 atm $[21,22]$ are currently available. Further refinement of the chemical kinetic model for mhx3d combustion needs a more extended experimental database.

In this work, we present a combined experimental investigation of the oxidation and combustion characteristics of $m h x 3 d$ using the facilities at ICARE-CNRS (speciation measurements in JSR at $1 \mathrm{~atm}$ ), Université de Bourgogne (ignition delay time measurements at 20 and 40 bar), Lund University (laminar burning velocity measurements at $1 \mathrm{~atm}$ ), and ICKC (speciation measurements in burner-stabilized laminar premixed flame at $1 \mathrm{~atm}$ ). Our original aim was to extend the available experimental database with the new measurement results and to validate the chemical kinetic mechanism previously developed for oxidation of $m h x 3 d$ [21] against the novel data. However, disagreements between the predictions and measurements motivated us to significantly revise the mechanism in order to provide a more robust version, able to reproduce the wide range of experimental data. Particularly, in order to adequately predict the laminar burning velocities, the base hydrocarbon chemistry in the original mechanism is replaced with the corresponding set of reactions adopted from the AramcoMech 3.0 [23]. The revision of thermochemistry data for the fuel molecule and fuel radicals allowed significant improvement of predictions of chemical speciation in the JSR at $1 \mathrm{~atm}$ and ignition delays measured at 20 and 40 bar. Further details are given in the sections below.

\section{Experimental methods}

\subsection{Speciation measurements in jet-stirred reactor at 1 atm}

Mhx3d oxidation under atmospheric pressure has been conducted in the experimental facility described in detail in previous publications $[21,24,25]$. The JSR, $4 \mathrm{~cm}$ in diameter, was made of fused silica and shown schematically in the Supplementary Material 2 in Fig. 2.1S. This reactor was used earlier for studies of $m h x 3 d$ oxidation at 10 atm [21]. In the current work, similarly to the previous study [21], three mixtures of different equivalence ratios $(\varphi=0.6,1.0$ and $2.0)$ were studied with a constant initial fuel mole fraction of $1000 \mathrm{ppm}( \pm 10 \%)$, at a pressure of $1 \mathrm{~atm}$. This high dilution level prevents temperature gradients inside the reactor. The flow rates of reactants were adjusted at each temperature to reach a constant residence time of $70 \mathrm{~ms}$. The liquid fuel ( $98 \%$, supplied by Sigma Aldrich) is brought by an HPLC pump to the entrance of a homemade vaporization system where it is atomized by a nitrogen flow and then vaporized in a heated chamber. The fuel $+\mathrm{N}_{2}$ mixture is carried to the reactor by a quartz capillary. The oxidizing stream $\left(\mathrm{O}_{2}+\mathrm{N}_{2}\right)$ is conveyed independently to prevent any reactions prior to the reactor. All gaseous flow rates are regulated by thermal mass flow controllers (Brooks 5850E). The two flows merged right ahead of the reactor, in which they are injected by four nozzles that ensure stirring. The sampling system consists of a fused-silica protected S-type thermocouple and a low pressure sonic fused silica probe. Samples are analyzed online by means of FTIR and stored at low pressure for offline $\mathrm{GC}$ analysis. Carbon balance was checked for each experiment and found to be within $\pm 10 \%$. The uncertainty on species mole fractions is estimated to be $\pm 15 \%$ based on uncertainties of the analytical measurements, temperature measurements $(<10 \mathrm{~K})$, pressure measurements $( \pm 0.1 \mathrm{~atm})$, the residence time $(<5 \%)$ and on inlet concentrations of the reactants $(<10 \%)$. 


\subsection{Burning velocity measurements with a heat-flux burner}

In the present work, the heat flux method for the stabilization of adiabatic premixed laminar flames on a flat flame burner at atmospheric pressure has been used [26]. This method has been extensively used for measuring laminar burning velocities $\left(\mathrm{S}_{\mathrm{L}}\right)$ of gaseous and liquid fuels. Detailed descriptions of the experimental setup, the measurement procedures, data processing and associated experimental uncertainties are given elsewhere [27].

The heat flux experimental setup is shown schematically in Supplementary Material 2 in Fig. 2.3S. Methyl trans-3-hexenoate (99.4\%, supplied by Sigma Aldrich) flow from a stainlesssteel tank pressurized with argon is metered by a Coriolis liquid mass flow controller and fed to a Controlled Evaporator Mixer (CEM), both from Bronkhorst High-Tech. The CEM consists of a control valve, a mixing device and a heat exchanger, the temperature of which is controlled by a temperature controller that is part of the system. Synthetic air $\left(21 \% \mathrm{O}_{2} / 79 \% \mathrm{~N}_{2}, 1 \%\right.$ relative uncertainty) has been provided by AGA in gas bottles. The required air flow rate is measured and regulated by means of two calibrated digital thermal mass flow controllers (Bronkhorst HighTech). A portion of the airflow is also used to stimulate the evaporation process as a mixing component and to transport the vapor. After the mixture is formed, the premixed charge flows through the plenum chamber of the heat flux burner, whose temperature $\left(\mathrm{T}_{\mathrm{g}}\right)$ is fixed by circulating water, pumped by a thermostatic bath. In the present experiments $\mathrm{T}_{\mathrm{g}}$ has been fixed at 338,348 and $353 \mathrm{~K}$. These temperatures have been chosen in order to cover a wider range of equivalence ratios, which is constrained by the vaporization limit of the mixture. In particular, at 338, 348 and $353 \mathrm{~K}$ the maximum equivalence ratio accessible to prevent condensation is respectively $1,1.2$ and 1.3 .

After that, the upward gas flow passes through the converging nozzle of the burner head and enters the perforated burner plate, where a flat flame is stabilized. The burner is composed of a $2 \mathrm{~mm}$-thick brass plate, perforated with $0.5 \mathrm{~mm}$-diameter holes at a pitch of $0.7 \mathrm{~mm}$, attached with thermal paste to the burner head. The burner plate has a nominal diameter of $3 \mathrm{~cm}$ and an effective perforation area of $6.7 \mathrm{~cm}^{2}$. It is surrounded by a heating jacket connected to a second water thermostatic bath, which keeps the burner plate preheated to a temperature higher than that of the plenum chamber. During the experiments, this temperature has been fixed at $368 \mathrm{~K}$.

After flame ignition, the positive temperature difference between the burner plate and the inlet mixture allows for stabilization of flat adiabatic flames, since the amount of heat lost by the flame to the burner is compensated by the gain to the unburned mixture as it enters the preheated burner plate. $S_{L}$ was determined by varying the flow rate of the gas mixture until a uniform radial temperature distribution over the burner plate, recorded by six T-type shielded thermocouples with very fine wires $(0.1 \mathrm{~mm})$ soldered into specific spaced holes over the burner plate, was achieved. For this condition, the velocity of the unburned gas is equal to the adiabatic laminar burning velocity. $\mathrm{S}_{\mathrm{L}}$ is an approximately linear function of flow velocity provided that the flame is stable at the adiabatic conditions. In this regard, Hermanns [28] found that the temperature difference between the burner plate and unburned gas mixture should be higher than $30 \mathrm{~K}$ (this value depends on the fuel mixture) to avoid flame instabilities. However, in the present experiments, this $\Delta \mathrm{T}$ has been set to 15-30 K, as explained, due to the vaporization limit. At these temperatures, the flames showed some instabilities around adiabatic conditions. Therefore, $\mathrm{S}_{\mathrm{L}}$ was determined by extrapolation from flat sub-adiabatic flames. An example of how $\mathrm{S}_{\mathrm{L}}$ is determined from subadiabatic flames can be found in [27] as well as an evaluation of the associated uncertainties.

\subsection{Ignition delay times measurements in a shock tube}

The ignition delay times were measured in a high-pressure shock tube over a temperature range of $1100-1500 \mathrm{~K}$ at $20 \mathrm{bar}$ and 40 bar. The experiments were performed with mixtures of $m h x 3 d(1 \%)+\mathrm{O}_{2}$ diluted in argon at equivalence ratios of $\varphi=0.6,1.2$ and 2.4. The experimental facility represents a stainless-steel tube with an inner diameter of $50 \mathrm{~mm}$ and separated by a double stainless-steel diaphragm into two parts, the driver section ( $4 \mathrm{~m}$ in length) and the driven section (5 $\mathrm{m}$ in length) [29]. The facility is shown schematically in Supplementary Material 2 Fig. 2.4S. 
The mixtures tested were prepared into two stainless-steel tanks based on the partial pressure method using high purity gases (greater than $99.995 \%$ for $\mathrm{Ar}$ and $\mathrm{O}_{2}$ ) and $m h x 3 d$ from the same supplier as in JSR. To prevent any contamination, the facility includes a vacuum system, a roughing pump and a turbo-molecular pump, which pumps down to $\sim 5 \mathrm{~Pa}$ the tube, the stainlesssteel tanks, the manifold and the previously frozen fuel tank. In order to avoid any condensation of the fuel, the tube, the tanks and the manifold are heated up to $80^{\circ} \mathrm{C}$ to allow the partial pressure of $m h x 3 d$ to be at least three times lower than its vapor pressure. The data acquisition system has a frequency of $1 \mathrm{MHz}$ and includes a NI Compact RIO that records the pressure signals from four individual piezoelectric pressure transducers PCB 113B22 in order to calculate the shock velocity and from a Kistler piezoelectric pressure transducer (603B1) located at the end wall to calculate the ignition delay time and determine post-shock pressure. It is defined as the time interval between the rebound of the shock wave at the end wall and the onset of combustion, commonly defined by a sudden change in pressure (inflection point). Example of the pressure readings obtained in experiment and ignition delay calculation presented in Supplementary Material 2 Fig. 2.5S. Postshock temperature is calculated from the shock wave velocity and the initial conditions based on the 1-D shock relations and the species thermodynamics using the chemical equilibrium software Gaseq [30] with an accuracy of $\pm 1 \%$ that corresponds to $\pm 10-15 \mathrm{~K}$ according to the uncertainty calculation proposed by Petersen et al. [31]. Accuracy of the ignition delay time measurements is estimated to be $10 \%$, however, in fuel-rich conditions at 40 bar pressure rise at the moment of ignition was less distinct and uncertainty was estimated in each point separately.

\subsection{Chemical speciation measurements in a premixed flame}

The chemical speciation in a laminar stoichiometric premixed $m h x 3 d / \mathrm{O}_{2} / \mathrm{Ar}$ flame stabilized on a flat flame burner at atmospheric pressure has been studied using the flame sampling molecular beam mass spectrometry. The experimental facility and procedures have been thoroughly described earlier and successfully used to study the chemical structure of atmosphericpressure flames including the flames of methyl and ethyl esters [9, 32-35]. Thus, only essential details are given below.

The burner and the fuel supply system are shown schematically in the Supplementary Material 2 in Fig. 2.6S. The burner matrix represented a perforated (orifices $0.5 \mathrm{~mm}$ in diameter with $0.7 \mathrm{~mm}$ center-to-center spacing between them) brass disk $16 \mathrm{~mm}$ in diameter and $3 \mathrm{~mm}$ thick. The matrix was fixed in a brass housing with water jacket. The burner temperature was maintained at $95^{\circ} \mathrm{C}$ by circulating water. Total flow rate of the cold mixture through the burner surface was $25 \mathrm{~cm}^{3} / \mathrm{s}$. The molar composition of the unburnt gas mixture was as following: $m h x 3 d / \mathrm{O}_{2} / \mathrm{Ar}=0.02 / 0.18 / 0.8$. Argon and oxygen flows were adjusted by mass flow controllers (MKS Instruments Inc.). Liquid $m h x 3 d$ was supplied to an electrically heated vaporizer through a steel capillary using a syringe pump. Argon flowing through the vaporizer entrained the fuel vapors via a heated line into the burner.

A schematic and a short description of the flame sampling molecular beam mass spectrometric setup is given in the Supplementary Material 2 in Fig. 2.7S. The flame gases were sampled along the centerline of the burner by a quartz conical probe with an orifice at the tip. The inner angle of the cone was $40^{\circ}$, the orifice diameter was $80 \pm 5 \mu \mathrm{m}$, the wall near the orifice was $80 \pm 5 \mu \mathrm{m}$ thick. A central portion of the molecular beam, which formed behind the sampling probe, was cut by a skimmer and entered the area of soft ionization by electrons. The spread in the electron energy values was determined by the width of the Maxwellian distribution of the electron gas and was $\pm 0.25 \mathrm{eV}$ (FWHM). The ions formed were analyzed by a quadrupole mass spectrometer. The electron energy was selected individually for each species measured so that, from one hand, to eliminate contributions of fragmented ions from other species to a mass peak of interest and, from the other hand, to have an adequate signal/noise ratio. The mole fraction profiles of the following species were measured in this work (at electron energies indicated in parentheses): $m h x 3 d$ (12.3 $\mathrm{eV}), \mathrm{O}_{2}(14.35 \mathrm{eV}), \mathrm{CO}(14.35 \mathrm{eV}), \mathrm{CO}_{2}(15.4 \mathrm{eV}), \mathrm{H}_{2} \mathrm{O}(15.4 \mathrm{eV}), \mathrm{H}_{2}(16.65 \mathrm{eV}), \mathrm{C}_{2} \mathrm{H}_{2}(12.3$ $\mathrm{eV}), \mathrm{CH}_{2} \mathrm{O}(11.5 \mathrm{eV}), \mathrm{C}_{2} \mathrm{H}_{4}(12.3 \mathrm{eV}), \mathrm{C}_{4} \mathrm{H}_{6}(12.3 \mathrm{eV}), \mathrm{C}_{2} \mathrm{H}_{6}(12.3 \mathrm{eV}), \mathrm{C}_{3} \mathrm{H}_{4}(12.3 \mathrm{eV}), \mathrm{CH}_{2} \mathrm{CO}$ 
(12.3 eV), $\mathrm{C}_{3} \mathrm{H}_{6}(12.3 \mathrm{eV}), \mathrm{CH}_{3}(13.2 \mathrm{eV})$. The burner was mounted on a translation mechanism with a micrometric screw to vary its vertical position (with the accuracy of $\sim \pm 10 \mu \mathrm{m}$ ) and scan over the distance between the burner surface and the sampling probe tip. This allowed signal intensity profiles for the mass peaks of interest to be measured.

All stable compounds were calibrated directly using the gas mixtures of known composition. The mole fractions of the reactants and major products $\left(m h x 3 d, \mathrm{O}_{2}, \mathrm{CO}, \mathrm{CO}_{2}, \mathrm{H}_{2} \mathrm{O}\right)$ were thus determined with an error of $\pm 15 \%$ of their maximum values in the flame. The calibration coefficient for $\mathrm{CH}_{3}$ was estimated using the relative ionization cross section method as was described before $[9,33,35,36]$. This method provided the $\mathrm{CH}_{3}$ mole fraction to be determined with the uncertainty of $\sim \pm 50 \%$. The mole fractions of all other intermediates were determined with an accuracy of $\pm 30 \%$.

To account for cooling effect of the sampling probe in the flame simulations the "disturbed" temperature profiles measured with a thin $\mathrm{Pt} / \mathrm{Pt}+10 \% \mathrm{Rh}$ thermocouple in the vicinity of the sampling probe tip (at $\sim 100 \mu \mathrm{m}$ upstream from it) were used as input data. The thermocouple was made of wire $0.02 \mathrm{~mm}$ in diameter and coated with an anti-catalytic layer of $\mathrm{SiO}_{2}$ (total diameter with coating was $\sim 0.05 \mathrm{~mm}$ ). The thermocouple readings were corrected for radiative heat losses as suggested elsewhere [37]. The error of the temperature measurements by the thermocouple was estimated to be $\sim \pm 40 \mathrm{~K}$.

\section{Kinetic mechanism development}

Substantial efforts have been undertaken in this work to update the detailed chemical kinetic mechanism for $m h x 3 d$ oxidation developed earlier by Zhang et al. [21]. The base hydrocarbon chemistry in the updated version is replaced by that of the recent version of Aramco mechanism 3.0 [23]. The sub-mechanism for mhx3d and smaller methyl esters (from methyl acetate up to methyl pentenoate) was also considerably revised to achieve an adequate reproduction of all available experimental data related to $m h x 3 d$ combustion. Resulting mechanism consists of 649 species and 3578 reactions. Its full version available in Supplementary material 1, along with the glossary showing chemical structure of all species, and designations used further in the text.

Particular attention has been paid to revisit the thermochemistry data for $m h \times 3 d$ and its primary radicals. Quantum chemistry calculations were conducted to compute thermochemical parameters of $m h x 3 d, m h \times 3 d 2 j, m h \times 4 d 3 j, m p e 4 d 3 j, m h \times 3 d m j$, haoj3d, $c 5 h 91-3, m h x 3 d 3 j, m h x 3 d 4 j$, $m h x 3 d 6 j$. Enthalpies of formation at $0 \mathrm{~K}$ for these species are calculated based on atomization approach. Composite methods of CBS-QB3 [38] and G4 [39] were used to calculate electronic energies of the molecules. Geometries and vibrational frequencies of all species involved were calculated at B3LYP/6-311G(2d,d,p) [40,41] level of theory, and 1-D internal rotational potentials were scanned at B3LYP/6-31G(d,p) level of theory. The heat of formation at $0 \mathrm{~K}$, vibrational frequencies, rotational constants and 1-D internal torsional potentials are used to calculate partition functions of each species changing along temperature with program of MESS [42]. With the rotational, vibrational and electronic partition functions, we calculated temperature-dependent thermochemical properties of enthalpies, entropies and heat capacities by calling to the ThermP code $[43,44]$ and converted to NASA polynomial format through PAC99 [43-45].Summary of these calculations are presented in Table. 1. Comparison with thermochemical parameters from [21] and [22] presented in the Supplementary Material 5.

\begin{tabular}{|c|c|c|c|c|c|c|c|c|c|}
\hline & $\Delta H_{, 298}^{\Theta}\left[\mathrm{kcal} \mathrm{mol}^{-1}\right]$ & $S_{298}^{\Theta}\left[\mathrm{cal} \mathrm{K}^{-1} \mathrm{~mol}^{-1}\right]$ & \multicolumn{5}{|c|}{$C_{p}(\mathrm{~T})\left[\mathrm{cal} \mathrm{K}^{-1} \mathrm{~mol}^{-1}\right]$} \\
\hline Species & & & 300 & 400 & 500 & 600 & 800 & 1000 & 1500 \\
\hline$m h x 3 d$ & -86.1 & 114.2 & 39.7 & 48.5 & 57.1 & 64.8 & 76.7 & 85.8 & 99.3 \\
\hline$m h x 3 d m j$ & -39.0 & 117.0 & 42.3 & 50.5 & 58.2 & 65.1 & 75.8 & 83.7 & 95.2 \\
\hline$m h x 3 d 2 j$ & -57.6 & 106.4 & 38.8 & 47.9 & 56.5 & 64.0 & 75.5 & 84.1 & 96.7 \\
\hline$m h x 3 d 3 j$ & -29.9 & 116.1 & 38.7 & 47.0 & 55.1 & 62.4 & 73.7 & 82.0 & 94.8 \\
\hline
\end{tabular}




\begin{tabular}{|c|c|c|c|c|c|c|c|c|c|}
\hline$m h \times 3 d 4 j$ & -30.5 & 115.8 & 38.3 & 46.9 & 55.1 & 62.4 & 73.6 & 82.1 & 94.7 \\
\hline$m h x 4 d 3 j$ & -54.6 & 112.3 & 37.6 & 46.6 & 55.1 & 62.7 & 74.2 & 82.8 & 95.6 \\
\hline$m h x 3 d 6 j$ & -37.6 & 118.6 & 39.5 & 47.7 & 55.8 & 63.0 & 74.0 & 82.4 & 94.8 \\
\hline mpe4d3j & -50.4 & 103.2 & 33.4 & 41.0 & 48.1 & 54.4 & 64.0 & 71.2 & 81.7 \\
\hline haoj3d & -36.7 & 105.3 & 33.9 & 41.5 & 48.4 & 54.4 & 63.2 & 69.8 & 79.7 \\
\hline c5h91-3 & 29.1 & 81.5 & 25.3 & 31.5 & 37.3 & 42.3 & 49.9 & 55.6 & 64.6 \\
\hline
\end{tabular}

Table 1. Thermochemical parameters calculated in this work.

Thermochemical parameters of other intermediate products of $m h x 3 d$ oxidation were evaluated using the latest version of Thergas software [46], which uses the group additivity method proposed by Benson [47]. Activation energies of unimolecular dissociation reactions of $m h x 3 d$ were updated according to the calculated dissociation energies of $\mathrm{C}-\mathrm{C}$ and $\mathrm{C}-\mathrm{O}$ bonds, presented in Fig. 2.

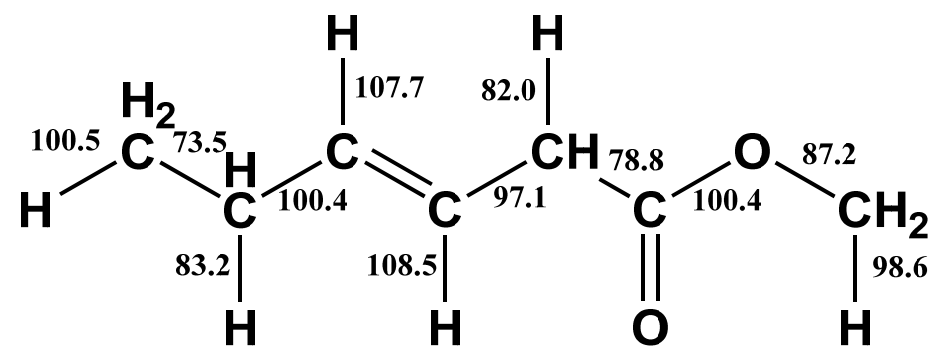

Fig. 2. Bond dissociation energies at $0 \mathrm{~K}$ in the $m h \times 3 d$ molecule, calculated at CBS-QB3 level of theory.

To reduce the overall size of the mechanism several tests were made to check if lowtemperature chemistry for intermediate esters and hydrocarbons produced during $m h x 3 d$ oxidation is also necessary. For this purpose, we removed one by one low-temperature submechanisms for each compound and then compared simulation results in all conditions. Our studies have shown that reactivity of $m h x 3 d / \mathrm{O}_{2}$ mixture at low temperatures is considerably sensitive to the reactions of small $\mathrm{C}_{3}$ intermediates (propene and methyl acetate) with molecular oxygen. However, lowtemperature reactions for larger $\mathrm{C}_{4}-\mathrm{C}_{6}$ esters and hydrocarbons were found to play a minor role and thus they were excluded from the final version of the mechanism. Other low-temperature reactions (together with their rate parameters) of $m h x 3 d$ and its primary radicals were kept unchanged as described earlier [21]. It is worth noting that according to our tests low-temperature chemistry had a considerable influence only in predicting JSR at $10 \mathrm{~atm}$ and ignition delay times, with minimal effects on simulations in other studied conditions. It can be noticed that after all modifications the resulting mechanism become large than previously, however model convergence and simulation speed improved considerably.

All kinetic simulations were performed using the modified Chemkin-II package [48]. Simulations of JSR and homogeneous ignition were performed using PSR and SENKIN modules respectively (with constant volume) [49, 50]. Burning velocity and burner stabilized flame simulations were performed using PREMIX code [51]. The sensitivity analysis was performed with brute-force method.

\section{Results and Discussion}

In this section, we provide a comparison between predictions with the updated mechanism and the experimental data, which are relevant to oxidation and combustion of $m h x 3 d$, available in the literature and the novel data reported in this study. All new experimental data presented in this work can be found in Supplementary Material 4 in digital form.

Fig. 3 demonstrates a comparison between the measurements and numerical simulation of laminar burning velocity of $m h x 3 d /$ air mixtures in a range of equivalence ratios and unburnt gas 
temperatures. The simulation results obtained using both the original mechanism of Zhang et al. [21] and the mechanism updated in this work are shown. As seen, the original mechanism [21] underpredicts the burning velocity values by around $30 \%$ in the whole range of equivalence ratios $(0.7-1.3)$.

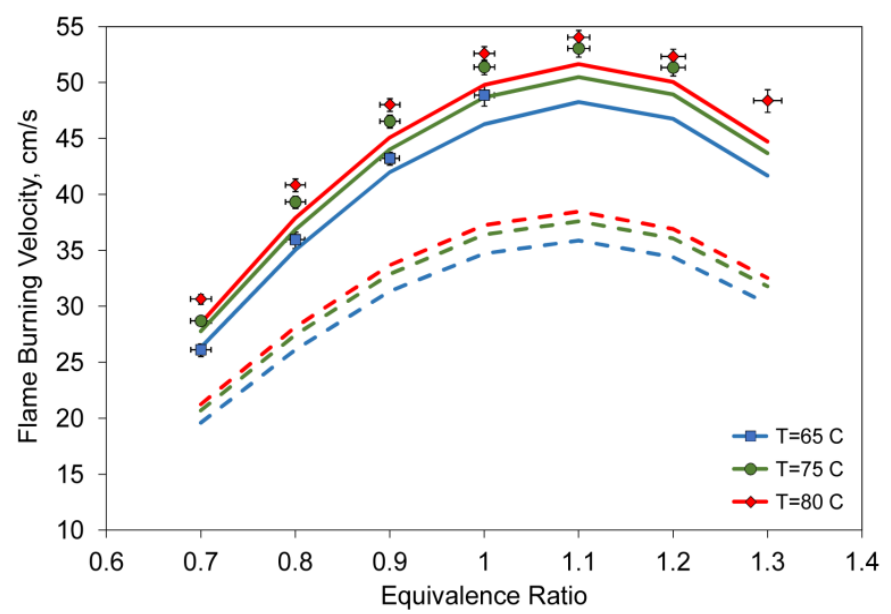

Fig. 3. Laminar burning velocity of $m h x 3 d$ /air mixtures (at different unburnt gas temperature T) as a function of equivalence ratio. Symbols: experiment, lines: modeling (dashed lines: original mechanism proposed by Zhang et al. [21], solid lines: updated mechanism).

The sensitivity analysis of the laminar burning velocity has shown that, as expected, it is mostly determined by the chemical kinetics of small $\mathrm{C}_{1}-\mathrm{C}_{4}$ hydrocarbons and oxygenated species and has a very weak sensitivity to the rate coefficients of reactions involving fuel and heavy intermediates. The updated kinetic model involves the reaction scheme for small hydrocarbons adopted from the well-validated AramcoMech 3.0 [23]. As a result, it predicts the experimental data shown in Fig. 3 much more adequately, however, also with some underestimation of the measured burning velocity values (by $\sim 5-7 \%$ ). It is possible to improve this agreement only by varying the rate coefficients of the reactions involving fuel and its specific products, but the required modifications appear to be too drastic and result in significant overestimation of the fuel reactivity, and therefore in the incorrect prediction of other experimental data sets. Nevertheless, we did not set the goal to minimize the remaining discrepancies between the predictions and the observations in Fig. 3 by modifying the rate coefficients from the base chemistry sub-mechanism (AramcoMech 3.0).

Therefore, the replacement of the base hydrocarbon submechanism with the more reliable and validated set of reactions from the AramcoMech 3.0 significantly improved the ability of the resultant mechanism to reproduce the burning velocities of $m h x 3 d /$ air mixtures. In this relation, in the following, only modeling results with the updated mechanism will be demonstrated and discussed. Modeling results with the old mechanism [21] without any modifications are presented in Supplementary Material 5. 


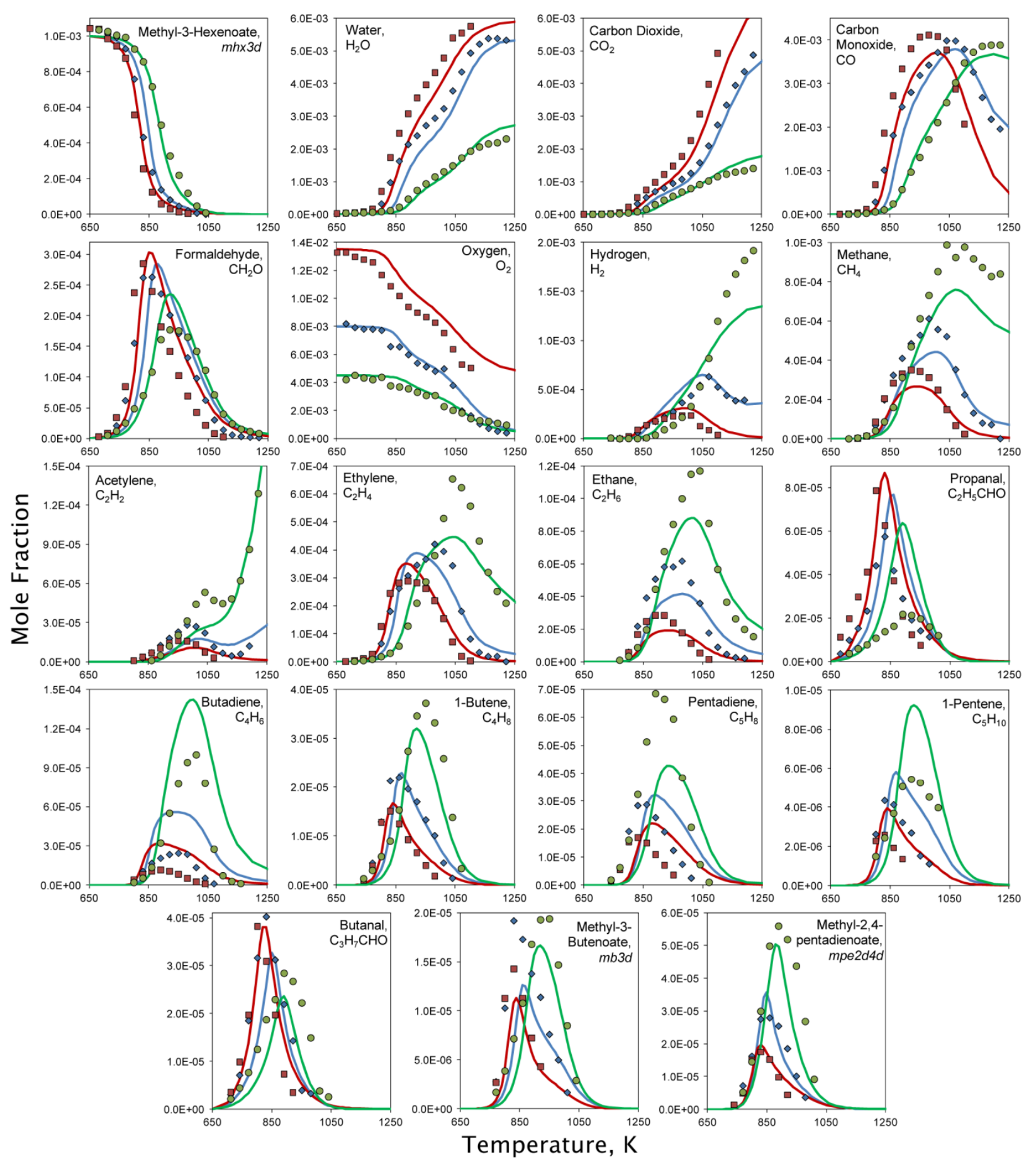

Fig. 4. Species mole fraction profiles in the jet-stirred reactor experiments at $10 \mathrm{~atm}$. Symbols: experimental data from [21] $(\circ-\varphi=2.0, \diamond-\varphi=1.0, \square-\varphi=0.6)$, lines: modeling with the updated mechanism (green $-\varphi=2.0$, blue $-\varphi=1.0$, red $-\varphi=0.6$ ).

Comparison between the experimental species mole fraction profiles obtained in the JSR at 10 atm by Zhang et al. [21] and numerical simulations with the new kinetic mechanism is presented in Fig. 4. As seen, the mechanism correctly predicts the mole fraction profiles of $m h x 3 d$, indicating that the consumption rate of the fuel and its total reactivity is adequately considered in the mechanism. Moreover, in general a good agreement between modeling and experiment for most products and intermediates measured by Zhang et al. is observed. 

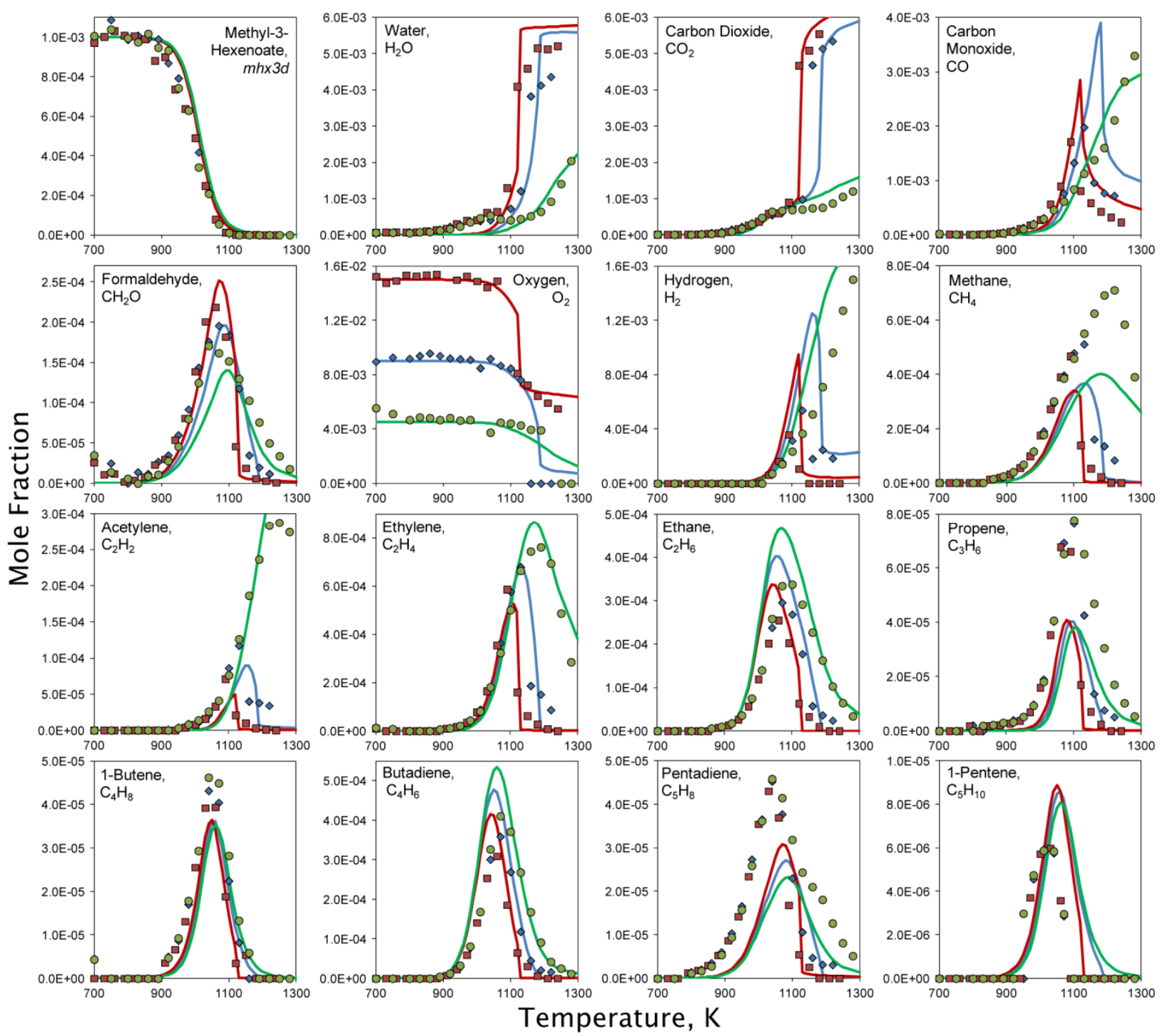

Fig. 5. Species mole fraction profiles measured in the jet-stirred reactor at $1 \mathrm{~atm}$.

Symbols: experiments $(\circ-\varphi=2.0, \diamond-\varphi=1.0, \square-\varphi=0.6)$, lines: modeling with the updated mechanism (green $-\varphi=2.0$, blue $-\varphi=1.0$, red $-\varphi=0.6$ ).

Fig. 5 presents the chemical speciation data measured in the JSR at $1 \mathrm{~atm}$. It is notable that at atmospheric pressure, conversion of intermediate species into final products abruptly rises at $1100 \mathrm{~K}$, and this is rather well reproduced by the updated model. As seen from Fig. 5, the fuel consumption becomes appreciable only at temperature around $900 \mathrm{~K}$. According to sensitivity analysis presented in Fig. 6, fuel consumption is controlled mostly by 2 important reactions of unimolecular $m h x 3 d$ decomposition (1 and 2), subsequent step of mpe4d3j dissociation (3), and one of the reactions of the fuel with $\mathrm{CH}_{3}$ radical (4):

$$
\begin{aligned}
& m h x 3 d=\mathrm{CH}_{3} \mathrm{OCO}+\mathrm{CH}_{2} \mathrm{CHCHCH}_{2} \mathrm{CH}_{3}, \\
& m h x 3 d=m p e 4 d 3 j+\mathrm{CH}_{3} . \\
& \mathrm{C}_{4} \mathrm{H}_{6}+\mathrm{CH}_{3} \mathrm{OCO}=m p e 4 d 3 j \\
& m h \times 3 d+\mathrm{CH}_{3}=m h x 3 d m j+\mathrm{CH}_{4}
\end{aligned}
$$

Reactions (1) and (2) are dissociation reactions of the weakest $\mathrm{C}-\mathrm{C}$ bonds in the $m h \times 3 d$ molecule (see Fig.2); mpe4d3j is the main product of reaction (2); and reaction (4) produces the fuel radical $m h \times 3 d m j$, which then dissociates in several steps producing $\mathrm{C}_{5} \mathrm{H}_{9}$. At atmospheric pressure, the mole fraction profiles of $m h x 3 d$ are practically identical for mixtures with different equivalence ratios. This also confirms that reactions of fuel with radical species probably have a lesser impact at this pressure on $m h x 3 d$ consumption, unlike observations at $10 \mathrm{~atm}$, where low-temperature chemistry has a much larger contribution to the fuel decomposition. In general, a good agreement 
between predictions and measurements of mole fraction profiles of most species can be seen in Fig. 5.

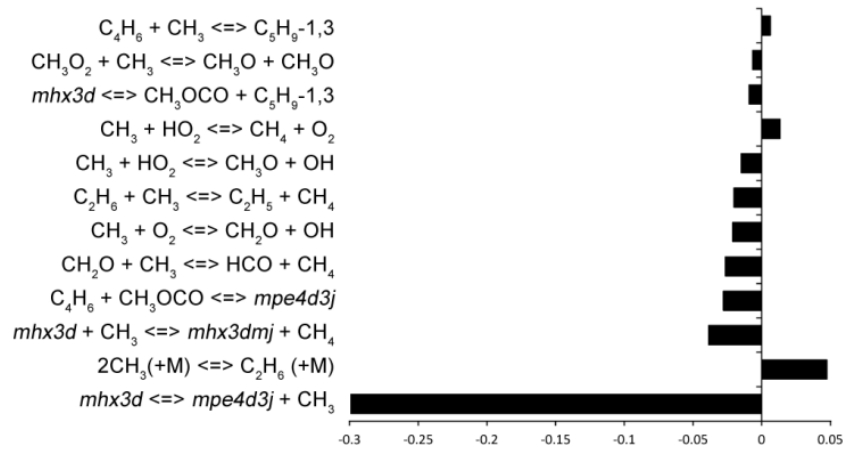

Fig. 6. Sensitivity coefficients for $m h x 3 d$ with respect to reaction rate constants at $1000 \mathrm{~K}$ in JSR at atmospheric pressure for $\varphi=1.0$.

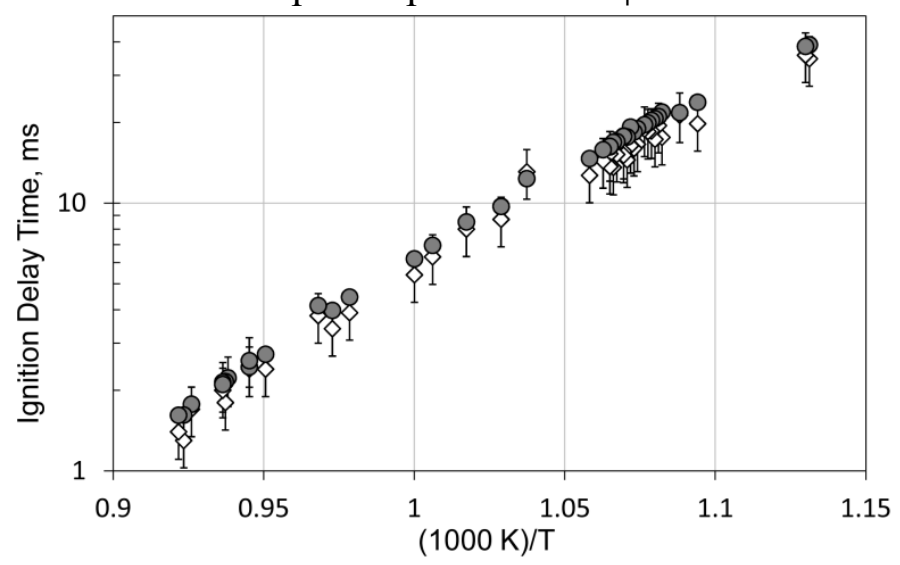

Fig. 7. Ignition delay times of $m h x 3 d / a i r$ mixtures with $\varphi=0.3$ in a range of temperatures at a pressure of 10.5 atm, diamonds: RCM experiment by Wagnon et al. [22], circles: simulations

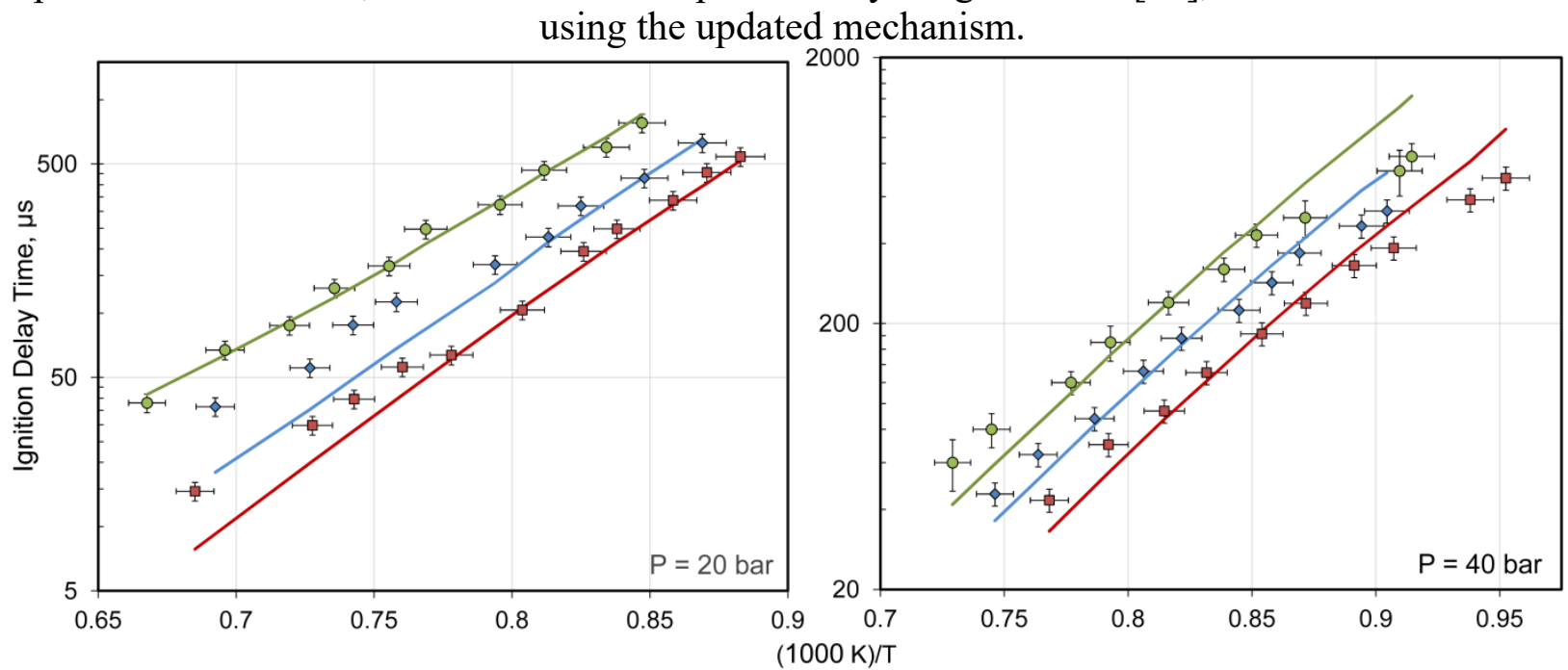

Fig. 8. Ignition delay times of $m h x 3 d(1 \%) / \mathrm{O}_{2} / \mathrm{Ar}$ mixtures in a range of temperatures at pressures 20 and 40 bar, symbols: experiment $(\circ-\varphi=2.4, \diamond-\varphi=1.2, \square-\varphi=0.6)$, lines: modeling using the updated mechanism.

A comparison between experimental results of ignition delay times measured by Wagnon et al. [22] in RCM at 10.5 atm in the range of initial temperatures $900-1100 \mathrm{~K}$ and simulations with the updated mechanism is presented in Fig. 7. The simulations were performed the same way as described by the authors of [22]. Although the calculated values of ignition delay times slightly overestimate the experimental ones, they are within the experimental uncertainty.

Ignition delay times measured in the shock tube between $1100-1500 \mathrm{~K}$ and at pressures of 20 and 40 bar are presented in Fig. 8. This figure also shows the simulation results obtained with the updated mechanism. At 20 bar, a good agreement between the experiment and simulations can 
be seen at temperatures lower than $1250 \mathrm{~K}$. However, at higher reflected shock temperature, the model underpredicts the measured values of ignition delays in fuel-lean and stoichiometric conditions. At 40 bar, discrepancies between experiment and simulations at high temperatures are smaller, but the model overestimates ignition delay times at temperatures lower than $1100 \mathrm{~K}$.

In order to understand possible reasons of the observed discrepancies, sensitivity coefficients of ignition delays were calculated for mixtures with $\varphi=1.2$ at $1150 \mathrm{~K}$ and $1340 \mathrm{~K}$. Fig. 9 demonstrates only the most sensitive reactions from the $m h x 3 d$ submechanism. As seen, the highest impact on ignition delay has the same reactions (1-4) that control reactivity in JSR at 1 atm. The ignition delay is also fairly sensitive to the rate parameters of several reactions of $m h x 3 d$ with $\mathrm{H}$ and $\mathrm{OH}$, as well as several radical decompositions. However, varying the rate constants of the reactions (1-3), we found that the calculated ignition delays are affected in the whole temperature range, i.e. we could not improve the predictions in high temperature range with keeping adequate predictions at temperatures lower than $1200 \mathrm{~K}$ for experiments at pressure of 20 bar.

As seen from Fig. 9, several reactions, including reaction (4), are considerably more sensitive at $1150 \mathrm{~K}$ than at $1340 \mathrm{~K}$. However, an increase of their rate constants caused an increase in concentrations of mpe $4 d 2 d, \mathrm{C}_{2} \mathrm{H}_{5} \mathrm{CHO}$ and other species in JSR simulations. In the end, we adjusted reaction rate constants to achieve a compromise between simulations in these two reactors. Thereby, we assume that a refinement of the base chemistry or revision of the $m h x 3 d$ oxidation scheme is needed to more accurately predict the ignition delay times without making worse the predictions of laminar burning velocity and reactivity in the JSR.

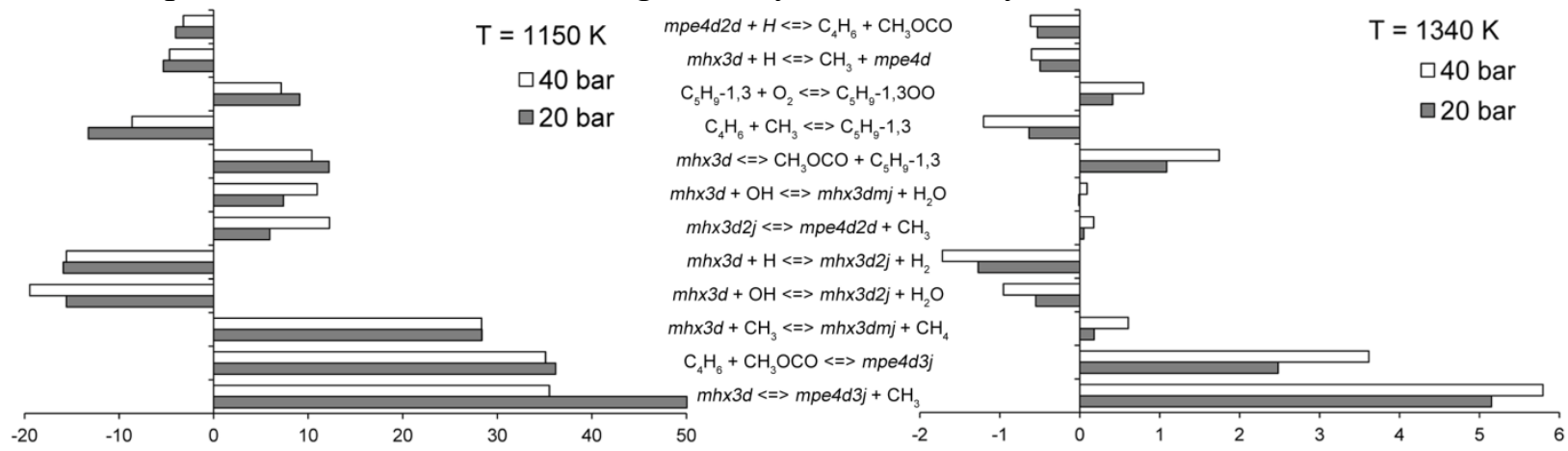

Fig. 9. Sensitivity of the ignition delays with respect to reaction rate constants for the mixtures with two different initial temperatures and $\varphi=1.2$. Only the most sensitive reactions

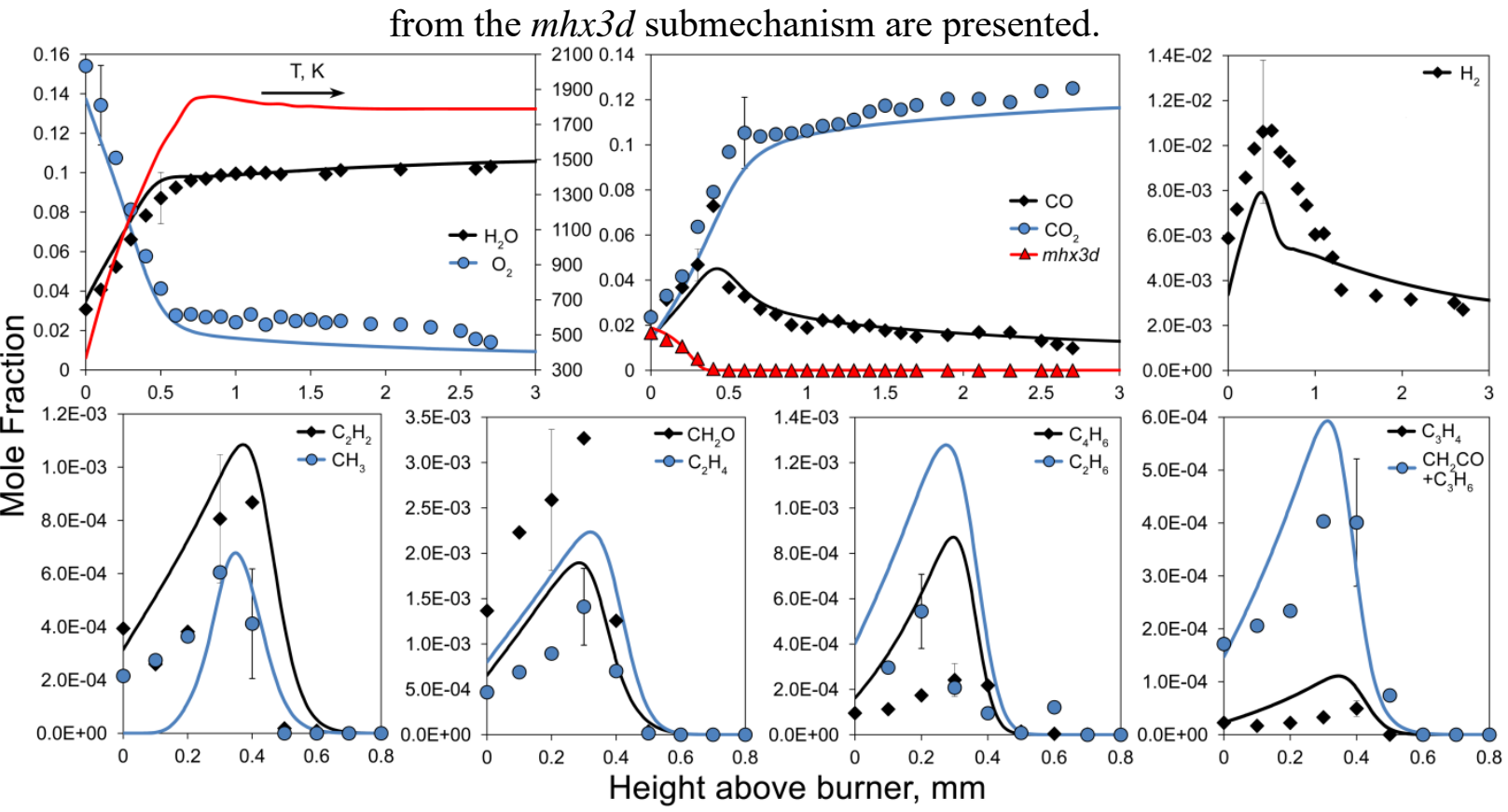


Fig. 10. Temperature and species mole fraction profiles in the laminar burner-stabilized flame of $m h \times 3 d / \mathrm{O}_{2} / \mathrm{Ar}$ mixture at $1 \mathrm{~atm}$, symbols: experiment, lines: simulation.

The updated kinetic mechanism was also validated against the experimental data on chemical speciation of the laminar premixed stoichiometric burner-stabilized $m h x 3 d / \mathrm{O}_{2} / \mathrm{Ar}$ flame at $1 \mathrm{~atm}$, which are shown in Fig. 10. This figure shows both experimental and simulated mole fraction profiles of reactants, major products and some small intermediates. As seen, despite some discrepancies between calculation results and experimental data for $\mathrm{C}_{4} \mathrm{H}_{6}, \mathrm{C}_{3} \mathrm{H}_{4}$ and $\mathrm{C}_{2} \mathrm{H}_{6}$, the mechanism adequately predicts the mole fraction profiles of the most species.

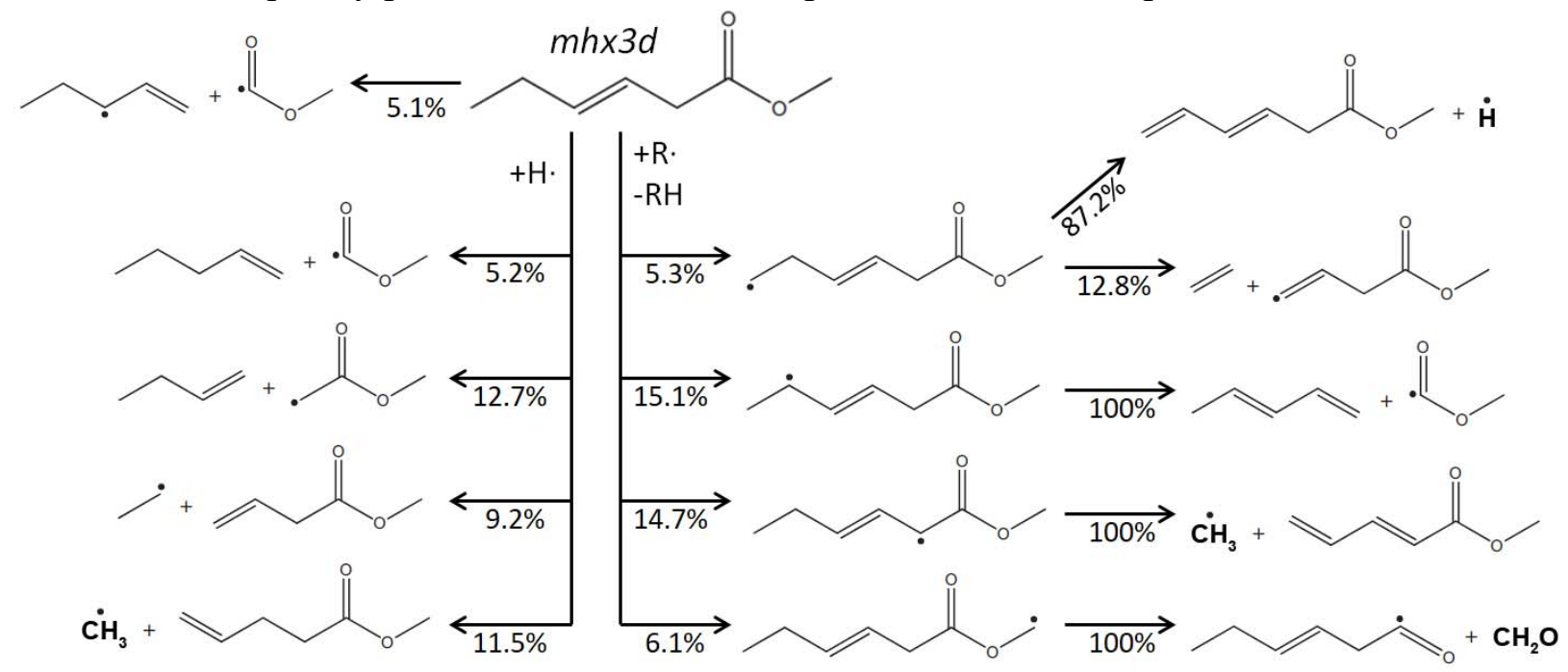

Fig. 11. Major reaction pathways of the $m h x 3 d$ consumption in the in the laminar burnerstabilized flame according to the updated kinetic mechanism.

An analysis of the primary reaction pathways of decomposition of the fuel molecule in the laminar burner-stabilized $m h x 3 d$ flame was carried out using the same method as described in previous studies [52] and presented in Fig. 11. The analysis was performed in terms of the contributions (in percents) of the integrated rate constant of each individual reaction to the total integrated rate of consumption of the selected species in the entire flame.

As seen from Fig. 11, unimolecular decomposition contributes only around 5\% of the total fuel consumption similarly as for saturated methyl esters [34]. Hence, despite the weaker C-C bonds in $m h x 3 d$ molecule comparatively to saturated esters, in burner stabilized flame conditions a diffusion flux of radicals from the high temperature zone still ensures near complete fuel consumption before unimolecular reactions become dominant. The fuel consumption in the flame occurs mostly through $\mathrm{H}$-abstraction by radicals and subsequent $\beta$-scission reactions. However, as it was mentioned above, unsaturated esters have additional channel of consumption through addition of radicals to the double bond with the subsequent decomposition. According to the analysis, total contribution of these reactions constitutes more than $40 \%$ of the total $m h \times 3 d$ consumption in flame (several reactions with a contribution less than $3 \%$ are not presented on the scheme). Accordingly, we suggest that more thorough study of this kind of reactions would be necessary for improvement of kinetic mechanisms of larger unsaturated esters.

\section{Conclusion}

An updated detailed chemical kinetic mechanism for oxidation and combustion of methyl3-hexenoate was proposed in this work. The AramcoMech 3.0 detailed chemical kinetic model for oxidation of small hydrocarbon and oxygenated intermediates was used as a base submechanism. The reactions for $m h x 3 d$ and smaller methyl esters (from methyl acetate up to methyl pentenoate) were adopted from the mechanism proposed earlier [21] for $m h x 3 d$ oxidation. The molecule geometries of the fuel and the fuel radicals were computed using quantum chemistry methods. These results were used to update the thermochemistry data for these species and the activation energies of the reactions of unimolecular decomposition of $m h \times 3 d$. 
The updated mechanism was validated against experimental data available at the moment in the literature (chemical speciation in the JSR at 10 atm and ignition delay times in the RCM) and novel measurement data reported in this work. Four types of measurements were conducted in this study to extend the experimental database on combustion of $m h x 3 d$. They are chemical speciation measurements during the oxidation in the JSR at 1 atm, ignition delay time measurements in the high-pressure shock tube at 20 and 40 bar, laminar burning velocity measurements at $1 \mathrm{~atm}$ in a heat flux burner, and chemical speciation measurements in the premixed burner-stabilized flame at $1 \mathrm{~atm}$.

The proposed mechanism was shown to adequately reproduce all experimental data mentioned above. However, some observed discrepancies between predictions and observations for ignition delay times and mole fraction profiles for several hydrocarbon intermediates may indicate the need for further mechanism refinement. A more thorough investigation of thermochemistry and chemical kinetics of oxidation of large intermediates (pentene, methyl hexenoates and pentenoates as well as their primary radicals) is required to improve the mechanism performance.

Nevertheless, despite the indicated deficiencies the mechanism catches all major tendencies observed in the experiments. Therefore, even at this stage it can be used as a basis for development of predictive detailed chemical kinetic models for combustion of heavier unsaturated methyl esters, which are representatives of components of real ester-based biodiesel.

\section{Acknowledgements}

Support from the CAPRYSSES project (ANR- 11-LABX-006-01) funded by ANR through the PIA (Programme d'Investissement d'Avenir) and Région Bourgogne-Franche Comté are gratefully acknowledged.

\section{References}

[1] A.K. Agarwal, J.G. Gupta, A. Dhar, Potential and challenges for large-scale application of biodiesel in automotive sector, Prog. Energy Combust. Sci. 61 (2017) 113-149.

[2] G. Knothe, L.F. Razon, Biodiesel fuels, Prog. Energy Combust. Sci. 58 (2017) 36-59.

[3] L. Coniglio, H. Bennadji, P.-A. Glaude, O. Herbinet, F. Billaud, Combustion chemical kinetics of biodiesel and related compounds (methyl and ethyl esters): Experiments and modeling Advances and future refinements, Prog. Energy Combust. Sci. 39 (2013) 340-382.

[4] Y. Zhang, Y. Yang, A.L. Boehman, Premixed ignition behavior of C9 fatty acid esters: A motored engine study, Combust. Flame 156 (2009) 1202-1213.

[5] C.K. Westbrook, C.V. Naik, O. Herbinet, W.J. Pitz, M. Mehl, S.M. Sarathy, H.J. Curran, Detailed chemical kinetic reaction mechanisms for soy and rapeseed biodiesel fuels, Combust. Flame 158 (2011) 742-755.

[6] S.M. Sarathy, S. Gail, S.A. Syed, M.J. Thomson, P. Dagaut, A comparison of saturated and unsaturated $\mathrm{C} 4$ fatty acid methyl esters in an opposed flow diffusion flame and a jet stirred reactor, Proc. Combust. Inst. 31 (2007) 1015-1022.

[7] S. Gaïl, S.M. Sarathy, M.J. Thomson, P. Diévart, P. Dagaut, Experimental and chemical kinetic modeling study of small methyl esters oxidation: Methyl (E)-2-butenoate and methyl butanoate, Combust. Flame 155 (2008) 635-650.

[8] B. Yang, C.K. Westbrook, T.A. Cool, N. Hansen, K. Kohse-Höinghaus, Photoionization mass spectrometry and modeling study of premixed flames of three unsaturated C5H8O2 esters, Proc. Combust. Inst. 34 (2013) 443-451.

[9] S. Dakshnamurthy, D.A. Knyazkov, A.M. Dmitriev, O.P. Korobeinichev, E.J.K. Nilsson, A.A. Konnov, K. Narayanaswamy, Experimental study and a short kinetic model for high-temperature oxidation of methyl methacrylate, Combust. Sci. Technol. 191 (2019) 1789-1814.

[10] K.C. Lin, J.Y.W. Lai, A. Violi, The role of the methyl ester moiety in biodiesel combustion: A kinetic modeling comparison of methyl butanoate and n-butane, Fuel 92 (2012) 16-26. 
[11] S. Bax, M.H. Hakka, P.-A. Glaude, O. Herbinet, F. Battin-Leclerc, Experimental study of the oxidation of methyl oleate in a jet-stirred reactor, Combust. Flame 157 (2010) 1220-1229.

[12] O. Herbinet, W.J. Pitz, C.K. Westbrook, Detailed chemical kinetic mechanism for the oxidation of biodiesel fuels blend surrogate, Combust. Flame 157 (2010) 893-908.

[13] W.Wang, S. Gowdagiri, M.A. Oehlschlaeger, Comparative Study of the Autoignition of Methyl Decenoates, Unsaturated Biodiesel Fuel Surrogates, Energy Fuels 27 (2013) 5527-5532.

[14] Y. Zhang, A.L. Boehman, Autoignition of binary fuel blends of n-heptane and C7 esters in a motored engine, Combust. Flame 159 (2012) 1619-1630.

[15] C.V. Naik, C.K. Westbrook, O. Herbinet, W.J. Pitz, M. Mehl, Detailed chemical kinetic reaction mechanism for biodiesel components methyl stearate and methyl oleate, Proc. Combust. Inst. 33 (2011) 383-389.

[16] P. Dagaut, S. Gaïl, M. Sahasrabudhe, Rapeseed oil methyl ester oxidation over extended ranges of pressure, temperature, and equivalence ratio: Experimental and modeling kinetic study, Proc. Combust. Inst. 31 (2007) 2955-2961.

[17] M.F. Campbell, D.F. Davidson, R.K. Hanson, C.K. Westbrook, Ignition delay times of methyl oleate and methyl linoleate behind reflected shock waves, Proc. Combust. Inst. 34 (2013) 419-425. [18] A. Rodriguez, O. Herbinet, F. Battin-Leclerc, A. Frassoldati, T. Faravelli, E. Ranzi, Experimental and modeling investigation of the effect of the unsaturation degree on the gas-phase oxidation of fatty acid methyl esters found in biodiesel fuels, Combust. Flame 164 (2016) 346362.

[19] C. Saggese, A. Frassoldati, A. Cuoci, T. Faravelli, E. Ranzi, A lumped approach to the kinetic modeling of pyrolysis and combustion of biodiesel fuels, Proc. Combust. Inst. 34 (2013) 427-434. [20] M.S. Stark, D.J. Waddington, Oxidation of propene in the gas phase, Int. J. Chem. Kinet. 27 (1995) 123-151.

[21] K. Zhang, C. Togbé, G. Dayma, P. Dagaut, Experimental and kinetic modeling study of transmethyl-3-hexenoate oxidation in JSR and the role of $\mathrm{C}=\mathrm{C}$ double bond, Combust. Flame 161 (2014) 818-825.

[22] S.W. Wagnon, D.M.A. Karwat, M.S. Wooldridge, C.K. Westbrook, Experimental and Modeling Study of Methyl trans-3-Hexenoate Autoignition, Energy Fuels 28 (2014) 7227-7234. [23] C-W. Zhou, Y. Li, U. Burke, C. Banyon, K.P. Somers, S. Khan, J.W. Hargis, T. Sikes, E.L. Petersen, M. AlAbbad, A. Farooq, Y. Pan, Y. Zhang, Z. Huang, J. Lopez, Z. Loparo, S.S. Vasu, H.J. Curran, An experimental and chemical kinetic modeling study of 1,3-butadiene combustion: Ignition delay time and laminar flame speed measurements, Combust. Flame 197 (2018) 423-438. [24] P. Dagaut, M. Cathonnet, J. Rouan, R. Foulatier, A. Quilgars, J. Boettner, F. Gaillard, H. James, A jet-stirred reactor for kinetic studies of homogeneous gas-phase reactions at pressures up to ten atmospheres ( $\approx 1 \mathrm{MPa})$, J. Phys. E Sci. Instrum. 19 (1986) 207-209.

[25] G. Dayma, F. Halter, F. Foucher, C. Togbé, C. Mounaim-Rousselle, P. Dagaut, Experimental and Detailed Kinetic Modeling Study of Ethyl Pentanoate (Ethyl Valerate) Oxidation in a Jet Stirred Reactor and Laminar Burning Velocities in a Spherical Combustion Chamber, Energy Fuels 26 (2012) 4735-4748.

[26] K.J. Bosschaart, L.P.H. de Goey, Detailed analysis of the heat flux method for measuring burning velocities, Combust. Flame 132 (2003) 170-180.

[27] V.A. Alekseev, J.D. Naucler, M. Christensen, E.J.K. Nilsson, E.N. Volkov, L.P.H. de Goey, A.A. Konnov, Experimental Uncertainties of the Heat Flux Method for Measuring Burning Velocities, Combust. Sci. Technol. 188 (2016) 853-894.

[28] R.T.E. Hermanns, Laminar burning velocities of methane-hydrogen-air mixtures, $\mathrm{PhD}$ thesis, Eindhoven University of Technology, Eindhoven, The Netherlands, 2007.

[29] H. El Merhubi, A. Kéromnès, G. Catalano, B. Lefort, L. Le Moyne, A high pressure experimental and numerical study of methane ignition, Fuel 177 (2016) 164-172.

[30] C. Morley, Gaseq version 0.79, http://www.gaseq.co.uk, 2005. 
[31] E.L. Petersen, M.J.A. Rickard, M.W. Crofton, E.D. Abbey, M.J. Traum, D.M. Kalitan, A facility for gas- and condensed-phase measurements behind shock waves, Meas. Sci. Technol. 16 (2005) 1716.

[32] O.P. Korobeinichev, S.B. Ilyin, V.V. Mokrushin, A.G. Shmakov, Destruction chemistry of dimethyl methylphosphonate in $\mathrm{H}_{2} / \mathrm{O}_{2} / \mathrm{Ar}$ flame studied by molecular beam mass spectrometry, Combust. Sci. Technol. 116-117 (1996) 51-67.

[33] A.M. Dmitriev, K.N. Osipova, D.A. Knyazkov, I.E. Gerasimov, A.G. Shmakov, O.P. Korobeinichev, Comparative Analysis of the Chemical Structure of Ethyl Butanoate and Methyl Pentanoate Flames, Combust. Explo. Shock Waves 54 (2018) 125-135.

[34] O.P. Korobeinichev, I.E. Gerasimov, D.A. Knyazkov, A.G. Shmakov, T.A. Bolshova, N. Hansen, C.K. Westbrook, G. Dayma, B. Yang, An experimental and kinetic modeling study of premixed laminar flames of methyl pentanoate and methyl hexanoate, Z. Phys. Chem. 229 (2015) 759-780.

[35] K.N. Osipova, A.M. Dmitriev, A.G. Shmakov, O.P. Korobeinichev, S.S. Minaev, D.A. Knyazkov, Combustion of ethyl acetate: the experimental study of flame structure and validation of chemical kinetic mechanisms, Mendeleev Commun. 29 (2019) 690-692.

[36] T.A. Cool, K. Nakajima, C.A. Taatjes, A. McIlroy, P.R. Westmoreland, M.E. Law, A. Morel, Studies of a Fuel-Rich Propane Flame with Photoionization Mass Spectrometry, Proc. Combust. Inst. 30 (2005) 1681-1688.

[37] W.E. Kaskan, The dependence of flame temperature on mass burning velocity, Symp. (Int.) Combust. 6 (1957) 134-141.

[38] J.A. Montgomery, M.J. Frisch, J.W. Ochterski, G.A. Petersson, A complete basis set model chemistry. VII. Use of the minimum population localization method, J. Chem. Phys. 112 (2000) $6532-6542$.

[39] L.A. Curtiss, P.C. Redfern, K. Raghavachari, Gaussian-4 theory, J. Chem. Phys. 126 (2007) 084108.

[40] A.D. Becke, Density-functional thermochemistry. III. The role of exact exchange, J. Chem. Phys. 98 (1993) 5648-5652.

[41] C. Lee, W. Yang, R.G. Parr, Development of the Colle-Salvetti correlation-energy formula into a functional of the electron density, Phys. Rev. B Condens. Matter 37 (1988) 785-789.

[42] Y. Georgievskii, J.A. Miller, M.P. Burke, S.J. Klippenstein, Reformulation and solution of the master equation for multiple-well chemical reactions, J. Phys. Chem. A 117 (2013) 1214612154.

[43] M. Keçeli, S.N. Elliott, Y.-P. Li, M.S. Johnson, C. Cavallotti, Y. Georgievskii, W.H. Green, M. Pelucchi, J.M. Wozniak, A.W. Jasper, S.J. Klippenstein, Automated computational thermochemistry for butane oxidation: A prelude to predictive automated combustion kinetics, Proc. Comb. Inst. 37 (2019) 363-371.

[44] S.J.K. Murat Keceli, B.J. McBride, S. Gordon, Quantum Thermochemistry Calculator (Qtc), 2018.

[45] B.J. McBride, S. Gordon, Computer Program for Calculating and Fitting Thermodynamic Functions, 1992.

[46] C. Muller, V. Michel, G. Scacchi, G.M. Côme, THERGAS: a computer program for the evaluation of thermochemical data of molecules and free radicals in the gas phase, J. Chim. Phys. 92 (1995) 1154-1178.

[47] S.W. Benson, Thermochemical Kinetics, Wiley, New York, 1976.

[48] R.J. Kee, F.M. Rupley, J.A. Miller, Chemkin-II: A fortran chemical kinetics package for the analysis of gas-phase chemical kinetics, Report No. SAND89-8009, Sandia National Laboratories, Livermore, CA, USA, 1989.

[49] A.E. Lutz, R.J. Kee, J.A. Miller, SENKIN: A Fortran program for predicting homogeneous gas phase chemical kinetics with sensitivity analysis, Report No. SAND-87-8248, Sandia National Laboratory, Livermore, CA, USA, 1987. 
[50] P. Glarborg, R.J. Kee, J.F. Grcar, J.A. Miller, PSR: A Fortran program for modeling wellstirred reactors, Report No. SAND-86-8209, Sandia National Laboratory, Livermore, CA, USA, 1986.

[51] R.J. Kee, J.F. Grcar, M.D. Smooke, J.A. Miller, PREMIX: A Fortran program for modeling steady laminar one-dimensional premixed names, Report No. SAND85-8240, Sandia National Laboratory, Livermore, CA, USA, 1985.

[52] D.A. Knyazkov, I.E. Gerasimov, N. Hansen, A.G. Shmakov, O.P. Korobeinichev, Photoionization mass spectrometry and modeling study of a low-pressure premixed flame of ethyl pentanoate (ethyl valerate), Proc. Combust. Inst. 36 (2017) 1185-1192. 